ISSN: 1130-2887 - eISSN: 2340-4396

DOI: https://doi.org/10.14201/alh.23821

\title{
GÉNERO Y PODER EN ARGENTINA. LAS ELITES EJECUTIVAS DE FERNÁNDEZ DE KIRCHNER, MACRI Y FERNÁNDEZ
}

\author{
Gender and power in Argentina. The executive elites of Fernández de Kirchner, \\ Macri and Fernández.
}

\author{
Paula Vera CANELO (1) pvcanelo@conicet.gov.ar ${ }^{1}$ \\ ${ }^{1}$ Consejo Nacional de Investigaciones Científicas y Técnicas (CONICET)
}

Envío: 2020-08-14

Aceptado: 2021-02-25

First View: 2021-04-08

Publicación: 2021-04-26

RESUMEN: El artículo analiza el vínculo entre género y poder en las elites gubernamentales del Ejecutivo Nacional durante las presidencias de Fernández de Kirchner (2011), Macri (2015) y Fernández (2019) en Argentina. El estudio sistemático de 857 puestos en ministerios, secretarías y subsecretarías muestra el grado de participación femenina; las tendencias a la masculinización/feminización de las áreas de gestión y las dependencias, y la relación entre cargo y género, identificando qué «techos de cristal» obstaculizan la paridad de género.

Palabras clave: paridad de género; elites gubernamentales; Poder Ejecutivo Nacional; Argentina.

ABSTRACT: The article analyzes the link between gender and power in the governmental elites of the National Executive during the presidencies of Fernández de Kirchner (2011), Macri (2015) and Fernández (2019) in Argentina. The systematic study of 857 positions in Ministries, Secretaries and Under Secretariesshows the degree of female participation; masculinization/feminization trends in management areas and agencies, and the relationship between position and gender, identifying which "glass ceilings» hinder gender parity.

Keywords: gender parity; governmental elites; National Executive Branch; Argentina. 


\section{INTRODUCCIÓN}

Un aspecto sobresaliente del debate sobre derechos de las mujeres e igualdad de género es que la representación política importa: el acceso de las mujeres a los cargos políticos, tanto legislativos como ejecutivos, es decisivo por muchos motivos. Entre ellos, de acuerdo con la literatura especializada, para posibilitar el acceso a la representación de nada menos que la mitad de la población, para profundizar la calidad democrática de las instituciones, para ampliar las agendas políticas, para fortalecer la competencia político-partidaria, para transformar los patrones de género presentes en la sociedad y estimular y reproducir, a su vez, una mayor tendencia a la participación femenina, para incorporar los intereses de las mujeres en el contenido de las políticas públicas (Araújo, 2009; Fernández Poncela, 2012; Martín, 2018; Martínez y Garrido, 2013; Ríos Tobar y Villar, 2005).

Fue especialmente durante los años noventa que, en América Latina, la deficiente representación política de las mujeres comenzó a ser considerada como un déficit de la democracia. Y a partir de un conjunto de acontecimientos fundamentales, entre los que sobresalen la Declaración de Atenas (1992), el Consenso de Quito (2007) y el Consenso de Brasilia (2010), comenzó a pensarse en la importancia de avanzar hacia lo que fue definido como «democracias paritarias» (Archenti y Tula, 2014).

Sin embargo, la desigualdad de género en el ámbito de la representación política y de los procesos de toma de decisiones sigue constituyendo una de las principales deudas de la democracia en América Latina. La persistente marginación de las mujeres de los órganos más importantes de representación y la falta de igualdad en el acceso a cargos públicos son algunas de las problemáticas señaladas por la literatura especializada a nivel internacional, regional y local. Ha sido señalado que los factores que impiden una competencia equilibrada de género en el plano político son múltiples: variables estructurales (por ejemplo, las brechas de ingreso o las desigualdades en el mercado de trabajo) y/o culturales e ideológicas (creencias o estereotipos sociales sobre las mujeres) (D’Alessandro, 2016; Fernández Poncela, 2012; Inglehart y Norris, 2003; Paxton y Kunovich, 2003; Reynolds, 1999; Rodríguez, 2003). También se demostró que los factores político-institucionales juegan un rol directo en la generación de sistemas de incentivos hacia una mayor representación política femenina (Abu-Zayd et al., 2002; Archenti y Tula, 2019; Araújo, 2009; Claveria, 2014; Craske y Molyneux, 2002; Krook y O’Brien, 2012; Luengo y Del Campo, 2008; Ríos Tobar y Villar, 2005; Verge y Claveria, 2018).

Uno de los mecanismos institucionales más utilizados para incentivar una presencia más equitativa de mujeres en distintos niveles del poder político fueron los cupos de género y las leyes de paridad. La Ley n. ${ }^{\circ}$ 24.012, aprobada en Argentina en 1991, fue la primera cuota legal a nivel mundial establecida para aumentar la representación femenina en los espacios parlamentarios nacionales. Esta iniciativa fue imitada por otros países latinoamericanos que incluyeron este tipo de mecanismos en sus legislaciones internas: México (1996), Paraguay (1996), Bolivia (1997), Brasil (1997), Costa Rica (1997), Ecuador (1997), Panamá (1997), Perú (1997), República Dominicana (1997), Venezuela (1997), Colombia (2000) y Honduras (2000) (Ríos Tobar y Villar, 2005). Las leyes de cupo incorporadas entre 1991 y 2000 en la región establecieron porcentajes mínimos de candidaturas femeninas con los que deben contar las listas electorales presentadas por los partidos políticos en los procesos eleccionarios, 
entre un $20 \%$ y un $40 \%$ aproximadamente. Sin embargo, y por ejemplo para el caso argentino, la implementación concreta de las leyes de cupo encontró numerosas resistencias en las organizaciones partidarias, que, lejos de habilitar el esperado avance progresivo hacia mayores espacios para las mujeres, les dieron a las mismas un cumplimiento «minimalista y burocrático» (Archenti y Tula, 2019).

A pesar de estos avances en el plano legislativo, varios estudios mostraron que los poderes ejecutivos nacionales y subnacionales, salvo excepciones, siguen resistiendo el avance hacia la paridad de género. Así lo indica la literatura internacional en general (Bego, 2014; De Winter, 1991; Fleischer y Seyfried, 2015; Inglehart y Norris, 2003; Jalalzai y Krook, 2010; Kenig y Barnea, 2009; Krook y O’Brien, 2012; Reynolds, 1999; Sotiropoulos y Bourikos, 2002) y la vinculada puntualmente con países latinoamericanos (Baldez, 2002; Basabe-Serrano, 2020; Jalalzai, 2014; Jalalzai y Krook, 2010; Whitford et al., 2007; Valdés, 2010), incluido el caso argentino (Canelo, 2019; Caminotti et al., 2011; Caminotti y Cogliano, 2019; Caminotti y Freidenberg, 2016). La tendencia general muestra que las mujeres no solo han sido una minoría y han estado ausentes de muchas áreas de gestión ejecutivas, sino que han sido designadas para ocupar los cargos de menor jerarquía o en las áreas menos decisivas (Escobar-Lemmon y Taylor-Robinson, 2008; Krook y O’Brien, 2012).

En Argentina y en otros países latinoamericanos la división del trabajo en el hogar y las concepciones tradicionales sobre género, fortalecidas por el resurgimiento en la región de gobiernos conservadores, se replicaron en la división del trabajo político (Giordano y Rodríguez, 2020). A partir de 2015 en Argentina, esas concepciones tradicionales, especialmente acentuadas en el perfil ideológico de la coalición de centro-derecha Cambiemos, contribuyeron al aumento de la desigualdad de género entre sus elites gubernamentales ejecutivas (Canelo, 2019; Canelo y Lascurain, 2017). Sin embargo, esta fuerza política también viabilizó el arribo de mujeres a cargos históricamente ocupados por varones: por ejemplo, la vicepresidencia de la Nación y la gobernación de la provincia de Buenos Aires, la más importante del país. En paralelo, la región asistía a una decidida expansión del movimiento de mujeres, que promovió políticas públicas propias de la agenda de género, como la legalización de la interrupción voluntaria del embarazo ${ }^{1}$, la prevención de los femicidios y de la violencia de género, entre otras, fortaleciendo su legitimidad en la escena pública y aumentando las demandas hacia una mayor representación femenina en los espacios de toma de decisiones.

Es cierto que los gabinetes, dependencias estratégicas para la organización y el funcionamiento del poder gubernamental, recibieron una gran atención de las ciencias sociales, especialmente de la ciencia política y la sociología $a^{2}$; como ha sido señalado, las elites políticas han sido probablemente uno de los asuntos más estudiados del siglo XX (Perissinotto y Codato, 2008, p. 7). Sin embargo, el interés por el vínculo entre género y elites ejecutivas es relativamente reciente, al menos para el caso argentino. Al igual que la literatura internacional

1. En la Argentina, esta demanda tomó estado parlamentario en 2018, hacia fines del gobierno de Mauricio Macri, y se transformó finalmente en ley durante el gobierno de Fernández, a fines de diciembre de 2020.

2. Ver, entre otros, Alcántara Sáez, 2006; Camerlo, 2013; Chasquetti et al., 2013; Codato et al., 2018; Dávila et al., 2013; Gené y Vommaro, 2018; Joignant y Güell, 2011; De Luca, 2012; Perelmiter et al., 2012; Pomares et al., 2014. 
comparada sobre género y gabinetes (Claveria, 2014; Escobar-Lemmon y Taylor-Robinson, 2005), la bibliografía observó únicamente el cargo más alto de la estructura (ministro/a) (Barnes et al., 2019; Canelo et al., 2015; Giorgi, 2014), sin analizar los cargos inmediatamente inferiores, y raras veces se involucró con estudios comparados en el largo plazo. Esto impide conocer, por ejemplo, qué posición ocupan las mujeres en las jerarquías internas de estos espacios ejecutivos, el perfil de género de las segundas líneas, las tendencias a largo plazo del reclutamiento o los factores estructurales que bloquean los avances hacia la paridad.

El presente artículo propone un estudio empírico del vínculo entre género y poder en las «elites gubernamentales» (Joignant, 2011) del Poder Ejecutivo Nacional durante las presidencias de Fernández de Kirchner (2011), Macri (2015) y Fernández (2019). Aborda los siguientes interrogantes: ¿Qué grado de participación tuvieron las mujeres en estas elites gubernamentales ejecutivas? ¿Cuáles fueron las dependencias y las áreas de gestión más feminizadas y cuáles las más masculinizadas? ¿Qué tipo de cargo jerárquico tendieron a ocupar las mujeres? ¿Qué «techos de cristal» obstaculizaron su ascenso a las más altas jerarquías políticas?

\section{TABLA 1. POSICIONES DE ELITE GUBERNAMENTAL POR DEPENDENCIA. PRESIDENCIAS DE FERNÁNDEZ DE KIRCHNER, MACRI Y FERNÁNDEZ}

\begin{tabular}{|c|c|c|c|c|c|}
\hline \multicolumn{2}{|c|}{$\begin{array}{l}\text { PRESIDENCIA DE F. } \\
\text { DE KIRCHNER (2011) }\end{array}$} & \multicolumn{2}{|l|}{$\begin{array}{l}\text { PRESIDENCIA } \\
\text { DE MACRI (2015) }\end{array}$} & \multicolumn{2}{|c|}{$\begin{array}{c}\text { PRESIDENCIA } \\
\text { DE FERNÁNDEZ (2019) }\end{array}$} \\
\hline DEPENDENCIA & POSICIONES & DEPENDENCIA & POSICIONES & DEPENDENCIA & POSICIONES \\
\hline $\begin{array}{l}\text { Ministerio de Economía } \\
\text { y Finanzas Públicas }\end{array}$ & 27 & $\begin{array}{l}\text { Ministerio de } \\
\text { Seguridad }\end{array}$ & 26 & $\begin{array}{l}\text { Jefatura de Gabinete } \\
\text { de Ministros }\end{array}$ & 30 \\
\hline $\begin{array}{l}\text { Jefatura de Gabinete de } \\
\text { Ministros }\end{array}$ & 25 & $\begin{array}{l}\text { Ministerio de } \\
\text { Agroindustria }\end{array}$ & 25 & $\begin{array}{l}\text { Ministerio de } \\
\text { Desarrollo Productivo }\end{array}$ & 22 \\
\hline $\begin{array}{l}\text { Ministerio de Desarrollo } \\
\text { Social }\end{array}$ & 19 & $\begin{array}{l}\text { Ministerio de } \\
\text { Producción }\end{array}$ & 24 & $\begin{array}{l}\text { Ministerio de } \\
\text { Economía }\end{array}$ & 20 \\
\hline $\begin{array}{l}\text { Ministerio de Justicia y } \\
\text { Derechos Humanos }\end{array}$ & 19 & $\begin{array}{l}\text { Jefatura de Gabinete } \\
\text { de Ministros }\end{array}$ & 23 & $\begin{array}{l}\text { Ministerio de } \\
\text { Desarrollo Social }\end{array}$ & 17 \\
\hline $\begin{array}{l}\text { Secretarías de la } \\
\text { Presidencia de la } \\
\text { Nación }\end{array}$ & 18 & $\begin{array}{l}\text { Ministerio del Interior, } \\
\text { Obras Públicas y } \\
\text { Viviendas }\end{array}$ & 21 & $\begin{array}{l}\text { Secretarías de la } \\
\text { Presidencia de la } \\
\text { Nación }\end{array}$ & 16 \\
\hline $\begin{array}{l}\text { Ministerio de } \\
\text { Planificación Federal, } \\
\text { Obras y Servicios } \\
\text { Públicos }\end{array}$ & 16 & $\begin{array}{l}\text { Ministerio de } \\
\text { Desarrollo Social }\end{array}$ & 20 & $\begin{array}{l}\text { Ministerio de } \\
\text { Educación }\end{array}$ & 15 \\
\hline $\begin{array}{l}\text { Ministerio de } \\
\text { Relaciones Exteriores } \\
\text { y Culto }\end{array}$ & 13 & $\begin{array}{l}\text { Ministerio de Energía y } \\
\text { Minería }\end{array}$ & 18 & $\begin{array}{l}\text { Ministerio de } \\
\text { Relaciones } \\
\text { Exteriores, Comercio } \\
\text { Internacional y Culto }\end{array}$ & 14 \\
\hline
\end{tabular}


PAULA VERA CANELO

GÉNERO Y PODER EN ARGENTINA. LAS ELITES EJECUTIVAS DE FERNÁNDEZ DE KIRCHNER, MACRI Y FERNÁNDEZ

\begin{tabular}{|c|c|c|c|c|c|}
\hline \multicolumn{2}{|c|}{$\begin{array}{l}\text { PRESIDENCIA DE F. } \\
\text { DE KIRCHNER (2011) }\end{array}$} & \multicolumn{2}{|c|}{$\begin{array}{l}\text { PRESIDENCIA } \\
\text { DE MACRI (2015) }\end{array}$} & \multicolumn{2}{|c|}{$\begin{array}{c}\text { PRESIDENCIA } \\
\text { DE FERNÁNDEZ (2019) }\end{array}$} \\
\hline DEPENDENCIA & POSICIONES & DEPENDENCIA & POSICIONES & DEPENDENCIA & POSICIONES \\
\hline Ministerio de Salud & 13 & Ministerio de Salud & 16 & $\begin{array}{l}\text { Ministerio de Justicia y } \\
\text { Derechos Humanos }\end{array}$ & 14 \\
\hline $\begin{array}{l}\text { Ministerio de } \\
\text { Agricultura, Ganadería } \\
\text { y Pesca }\end{array}$ & 13 & $\begin{array}{l}\text { Ministerio de } \\
\text { Relaciones Exteriores } \\
\text { y Culto }\end{array}$ & 15 & $\begin{array}{l}\text { Ministerio de } \\
\text { Seguridad }\end{array}$ & 13 \\
\hline $\begin{array}{l}\text { Ministerio de Trabajo, } \\
\text { Empleo y Seguridad } \\
\text { Social }\end{array}$ & 12 & $\begin{array}{l}\text { Ministerio de Hacienda } \\
\text { y Finanzas Públicas }\end{array}$ & 15 & Ministerio de Defensa & 13 \\
\hline Ministerio de Industria & 12 & $\begin{array}{l}\text { Ministerio de } \\
\text { Transporte }\end{array}$ & 15 & Ministerio del Interior & 12 \\
\hline Ministerio de Seguridad & 10 & Ministerio de Defensa & 14 & Ministerio de Salud & 12 \\
\hline Ministerio de Defensa & 10 & $\begin{array}{l}\text { Ministerio de Justicia y } \\
\text { Derechos Humanos }\end{array}$ & 13 & $\begin{array}{l}\text { Ministerio de } \\
\text { Agricultura, Ganadería } \\
\text { y Pesca }\end{array}$ & 12 \\
\hline $\begin{array}{l}\text { Ministerio de } \\
\text { Educación }\end{array}$ & 8 & $\begin{array}{l}\text { Ministerio de Trabajo, } \\
\text { Empleo y Seguridad } \\
\text { Social }\end{array}$ & 13 & $\begin{array}{l}\text { Ministerio de Trabajo, } \\
\text { Empleo y Seguridad } \\
\text { Social }\end{array}$ & 10 \\
\hline $\begin{array}{l}\text { Ministerio de } \\
\text { Ciencia, Tecnología e } \\
\text { Innovación Productiva }\end{array}$ & 7 & $\begin{array}{l}\text { Ministerio de } \\
\text { Educación y Deportes }\end{array}$ & 13 & $\begin{array}{l}\text { Ministerio de Turismo } \\
\text { y Deportes }\end{array}$ & 10 \\
\hline Ministerio de Turismo & 5 & $\begin{array}{l}\text { Ministerio de } \\
\text { Modernización }\end{array}$ & 13 & $\begin{array}{l}\text { Ministerio de las } \\
\text { Mujeres, Géneros y } \\
\text { Diversidad }\end{array}$ & 10 \\
\hline \multirow[t]{6}{*}{ Ministerio del Interior } & 5 & $\begin{array}{l}\text { Secretarías de la } \\
\text { Presidencia de la } \\
\text { Nación }\end{array}$ & 11 & $\begin{array}{l}\text { Ministerio de } \\
\text { Ciencia, Tecnología e } \\
\text { Innovación }\end{array}$ & 10 \\
\hline & & Ministerio de Cultura & 10 & $\begin{array}{l}\text { Ministerio de } \\
\text { Transporte }\end{array}$ & 9 \\
\hline & & $\begin{array}{l}\text { Ministerio de } \\
\text { Ambiente y Desarrollo } \\
\text { Sustentable }\end{array}$ & 9 & $\begin{array}{l}\text { Ministerio de } \\
\text { Desarrollo Territorial y } \\
\text { Hábitat }\end{array}$ & 9 \\
\hline & & Ministerio de Turismo & 9 & $\begin{array}{l}\text { Ministerio de } \\
\text { Ambiente y Desarrollo } \\
\text { Sostenible }\end{array}$ & 8 \\
\hline & & $\begin{array}{l}\text { Ministerio de } \\
\text { Ciencia, Tecnología e } \\
\text { Innovación Productiva }\end{array}$ & 7 & $\begin{array}{l}\text { Ministerio de Obras } \\
\text { Públicas }\end{array}$ & 7 \\
\hline & & $\begin{array}{l}\text { Ministerio de } \\
\text { Comunicaciones }\end{array}$ & 6 & Ministerio de Cultura & 6 \\
\hline 17 & 232 & 22 & 336 & 22 & 289 \\
\hline
\end{tabular}

Fuente: Observatorio de las Elites CITRA (CONICET-UMET). 
Para ello, realiza un relevamiento sistemático y exhaustivo de las variables cargo ocupado y sexo del conjunto de los 857 individuos designados para ocupar las posiciones de elite gubernamental de ministro, secretario, subsecretario y cargos con jerarquía equivalente. Para preservar la comparabilidad entre los elencos de 2011, 2015 y 2019, este artículo trabaja con las elites gubernamentales iniciales, es decir, con las efectivamente designadas entre el momento de asunción de cada presidente (en la Argentina, durante el mes de diciembre) y mediados de marzo del año siguiente. La reconstrucción de las correspondientes estructuras orgánicas, variables en el tiempo, fue realizada a partir de los respectivos organigramas de la Administración Nacional centralizada (no se incluyó la Administración Descentralizada) hasta el nivel de subsecretaría inclusive. La fuente principal, tanto para las designaciones como para la reconstrucción de la estructura, fue el Boletín Oficial de la República Argentina.

La elite gubernamental de la expresidenta Cristina Fernández de Kirchner estuvo integrada por 232 funcionarios y funcionarias distribuidos en 15 ministerios, la Jefatura de Gabinete de Ministros (JGM) y las Secretarías de la Presidencia de la Nación (SP), que en este artículo son consideradas en conjunto. La del expresidente Mauricio Macri, por un total de 336 individuos designados en 20 ministerios, la JGM y las SP. Y la de Alberto Fernández, actual presidente argentino, por 289 funcionarios distribuidos en 22 dependencias (20 ministerios, JGM y SP) (Tabla 1).

\section{PARTICIPACIÓN DE LAS MUJERES EN LAS ELITES GUBERNAMENTALES}

De acuerdo con la bibliografía disponible para el caso argentino, que como mencionamos analiza solamente la posición de ministro o ministra, a lo largo de los 157 años que se extienden entre 1854 (año de asunción del primer gobierno nacional regido por la Constitución de 1853) y diciembre de 2011, solo un $1,72 \%$ de estos altos funcionarios fueron mujeres (Giorgi, 2014). Asimismo, durante el período que se extiende entre 1976 (año del último golpe cívico militar argentino) y 2001 (caída del gobierno democrático de Fernando de la Rúa) esa cifra asciende a un 2,8\% promedio (Canelo et al., 2015).

A pesar de que su presencia fue aumentando en el tiempo, las mujeres fueron siempre una minoría dentro del alto funcionariado del Ejecutivo Nacional argentino. El Gráfico 1 muestra el sexo de las elites gubernamentales ejecutivas reclutadas por Fernández de Kirchner, Macri y Fernández.

Los elencos ejecutivos iniciales de Fernández de Kirchner y de Macri, más allá de haberse tratado de una presidenta mujer y de un presidente hombre, y de sus profundas diferencias ideológicas y de contenido de sus políticas públicas, mantuvieron un reclutamiento de género muy similar. En ninguno de los dos casos las mujeres llegaron a un cuarto del total de altos funcionarios. Pero en 2019 los elencos de Fernández marcaron un récord de género: las funcionarias mujeres ocuparon el $37,37 \%$ del total de los cargos más altos. 


\section{GRÁFICO 1. SEXO DE LA ELITE GUBERNAMENTAL EJECUTIVA (\%). PRESIDENCIAS DE F. DE KIRCHNER, MACRI Y FERNÁNDEZ}

100

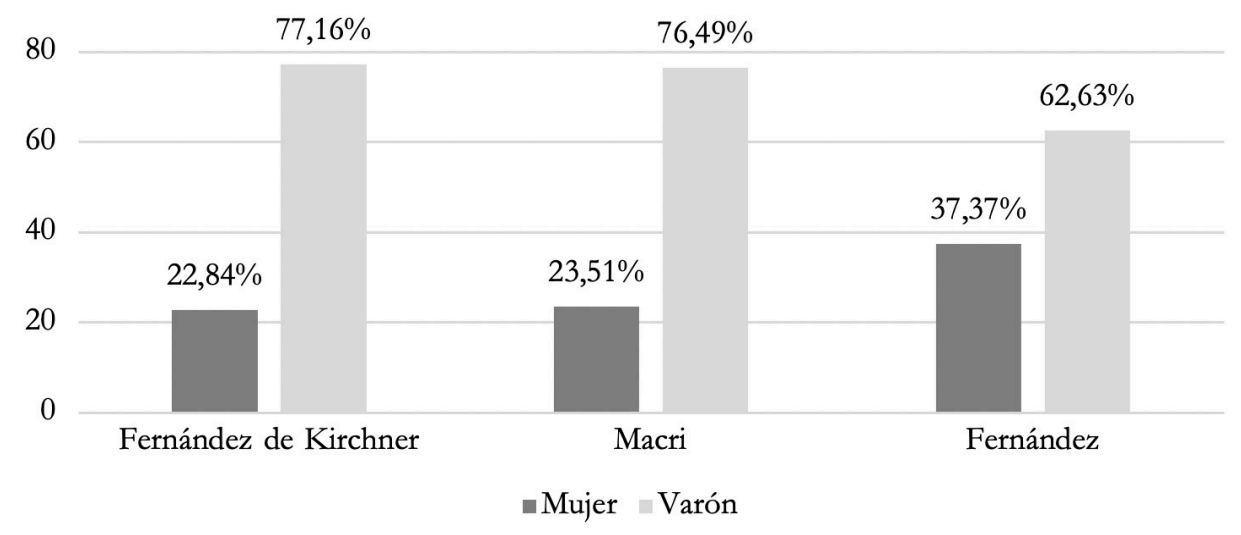

Fuente: Observatorio de las Elites CITRA (CONICET-UMET).

\section{PARTICIPACIÓN DE FUNCIONARIAS MUJERES POR DEPENDENCIA}

Las tendencias generales mencionadas en la sección anterior se complejizan al observar la distribución del personal político femenino ya no en el total, sino en cada dependencia (Gráficos 2, 3 y 4).

La elite ejecutiva durante la segunda presidencia de Cristina Fernández de Kirchner (Gráfico 2) muestra una importante desigualdad de género, con indicadores lejanos a la paridad en casi todas las dependencias. Con un promedio general del 22,84 \% de altas funcionarias, solo el Ministerio de Seguridad (conducido entonces por una mujer, Nilda Garré) apenas alcanzó la paridad entre hombres y mujeres. Los tres ministerios más feminizados fueron Seguridad (50 \%), Ciencia, Tecnología e Innovación Productiva (42,86 \%) y Trabajo, Empleo y Seguridad Social (41,67\%).

Algunas de las carteras consideradas «tradicionalmente femeninas», como Desarrollo Social y Educación, muestran indicadores de género apenas sobre el promedio, mientras que las económicas (Economía, Agricultura o Planificación) y las políticas (Secretarías de la Presidencia, Jefatura o Interior) se presentan muy masculinizadas. Las tres dependencias con mayor desigualdad de género en 2011 son Defensa (10\% de mujeres), Agricultura (7,69\%), Planificación (6,25\%) e Interior, donde no existe presencia femenina. 


\section{GRÁFICO 2. PARTICIPACIÓN DE MUJERES EN LA ELITE GUBERNAMENTAL EJECUTIVA DURANTE LA PRESIDENCIA DE F. DE KIRCHNER, POR DEPENDENCIA $(\%)$}

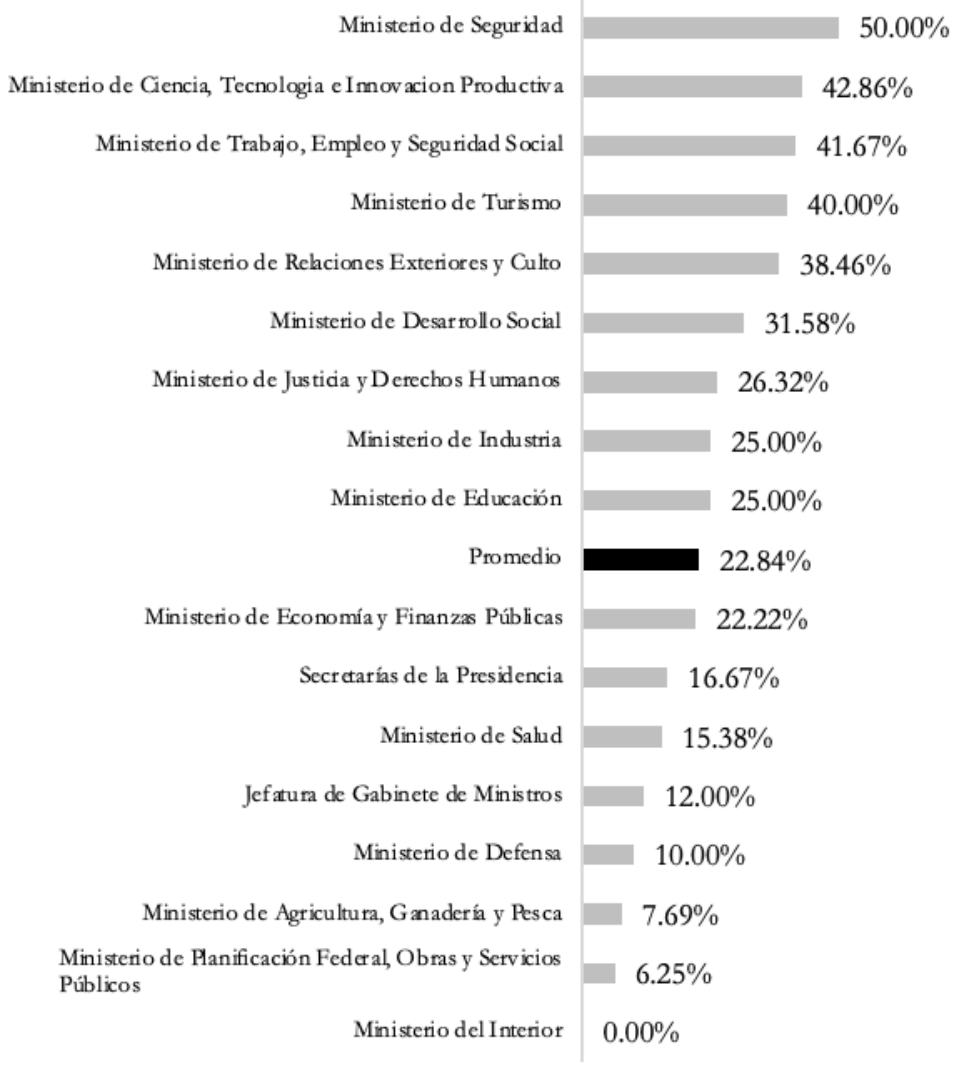

Fuente: Observatorio de las Elites CITRA (CONICET-UMET).

La elite gubernamental de Mauricio Macri (Gráfico 3) también presentó una importante desigualdad de género. Se observa una sola dependencia donde las mujeres fueron mayoría: el Ministerio de Desarrollo Social (60\%), conducido entonces por una mujer, Carolina Stanley. Ninguna otra dependencia superó el $40 \%$ de mujeres. Los ministerios con mayor presencia femenina, además de Desarrollo Social, fueron Salud (37,50 \%) y Relaciones Exteriores (también entonces conducido por una mujer, Susana Malcorra), Comunicaciones y Ambiente, todos con un tercio de mujeres en sus cúpulas $(33,33 \%)$. 


\section{GRÁFICO 3. PARTICIPACIÓN DE MUJERES EN LA ELITE GUBERNAMENTAL EJECUTIVA DURANTE LA PRESIDENCIA DE MACRI, POR DEPENDENCIA (\%)}

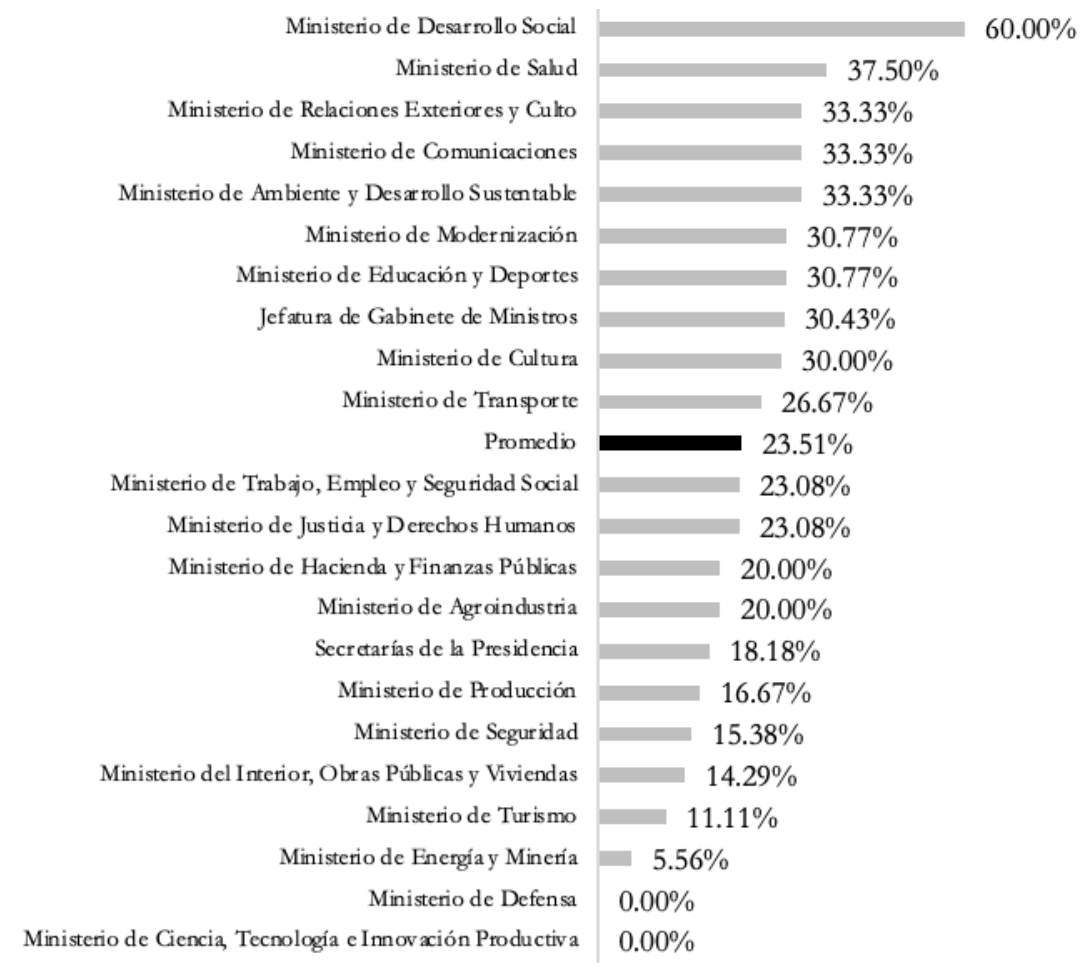

Fuente: Observatorio de las Elites CITRA (CONICET-UMET).

Todas las áreas que en 2011 se habían mostrado más feminizadas se masculinizaron en 2015. En Seguridad, las mujeres se redujeron del $50 \%$ al 15,38 \%; en Trabajo, del 41,67 \% al 23,08 \%, y en Ciencia, Tecnología e Innovación Productiva del 42,86 \% a 0 \%.

Las dependencias con funciones más económicas o políticas nuevamente quedaron por debajo del promedio en términos de presencia de mujeres: por un lado, Hacienda y Finanzas y Agroindustria (ambas $20 \%$ ), Producción (16,67 \%) y Energía y Minería (5,56 \%) y, por otro, las Secretarías de la Presidencia (18,18 \%) e Interior (14,29\%). Hubo dos dependencias que no reclutaron ninguna mujer: Defensa y Ciencia, Tecnología e Innovación Productiva. 


\section{GRÁFICO 4. PARTICIPACIÓN DE MUJERES EN LA ELITE GUBERNAMENTAL EJECUTIVA DURANTE LA PRESIDENCIA DE FERNÁNDEZ, POR DEPENDENCIA (\%)}

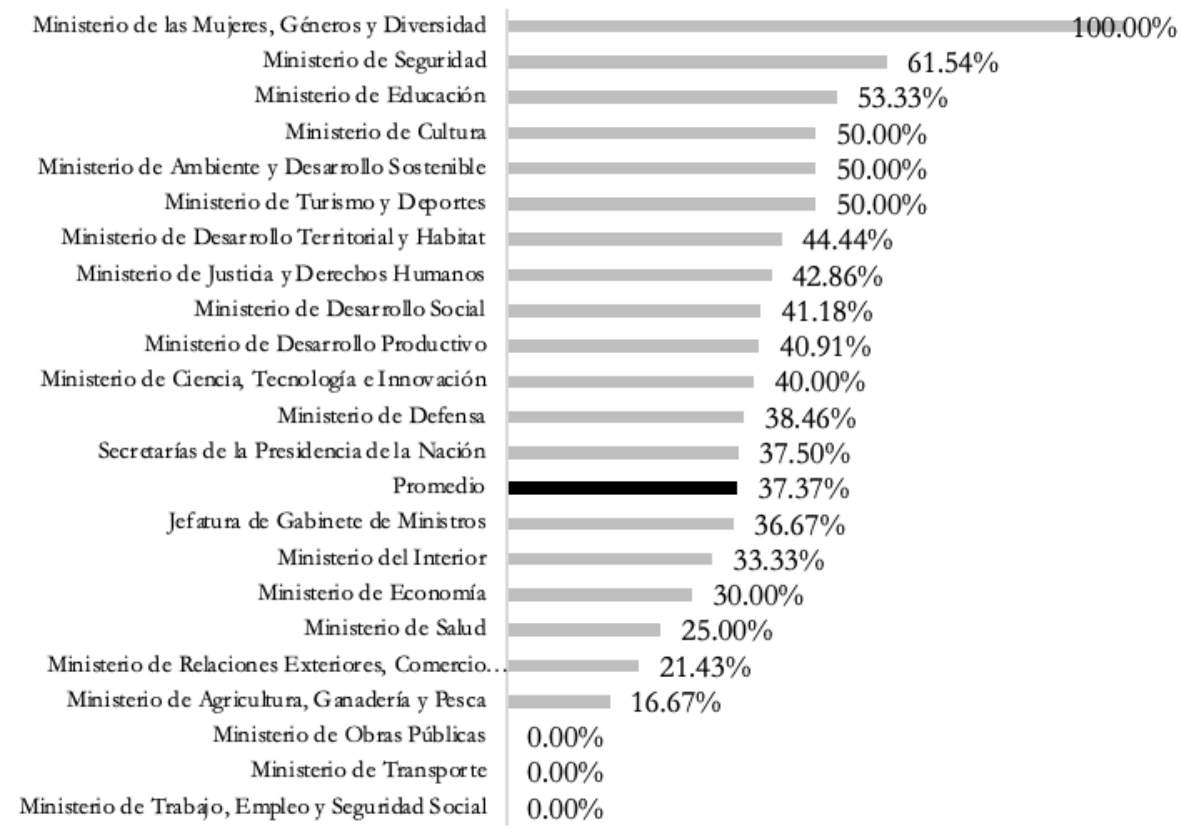

Fuente: Observatorio de las Elites CITRA (CONICET-UMET).

La composición de género por dependencia en el gobierno de 2019 (Gráfico 4) muestra un panorama bastante diferente. Fernández concretó la creación, por primera vez en la estructura del gabinete argentino, del Ministerio de las Mujeres, Géneros y Diversidad, cuya cúpula estaba integrada enteramente por mujeres, entre ellas la ministra Elizabeth Gómez Alcorta. El segundo ministerio con mayor presencia de mujeres es el Ministerio de Seguridad, con un 61,54 \% y también conducido por una mujer, Sabina Frederic. En tercer lugar se encuentra el Ministerio de Educación, con un 53,33 \% de personal político femenino. Los siguen, con paridad entre hombres y mujeres, Turismo y Deportes y Cultura y Ambiente (50 \%); y luego Desarrollo Territorial y Hábitat (44,44\%), Justicia y Derechos Humanos $(42,86 \%)$ y Desarrollo Social $(41,18 \%)$.

Las elites gubernamentales que acompañaron a Fernández muestran una orientación más clara hacia la paridad de género que los elencos anteriores. Sobre 22 dependencias, 6 alcanzan la paridad (50\% de mujeres) o invierten la mayoría masculina (más del $50 \%$ de mujeres), mientras que otras 5 superan el $40 \%$ de mujeres.

La elite gubernamental ejecutiva de Fernández trajo otras novedades. Por ejemplo, como una excepción a la masculinización de las áreas económicas, el Ministerio de Desarrollo 
Productivo colocó el 41 \% de su cúpula en manos de personal político femenino. También en las áreas políticas creció la presencia de mujeres: en las Secretarías de la Presidencia aumentó del 18,18 \% al 37,50 \%; en Interior, del 14,29 \% a ocupar un tercio de la cúpula; y en JGM, del $30,43 \%$ al 36,67\%. También son destacables los casos de Ciencia, Tecnología e Innovación y Defensa, donde en 2019 se reposicionaron las mujeres, ausentes desde 2015.

Es importante mencionar que, más allá de estos avances, en 2019 también creció la cantidad de ministerios donde no fue designada ninguna mujer: Obras Públicas, Transporte y Trabajo, los tres conducidos por ministros hombres.

\section{TENDENCIAS A LA MASCULINIZACIÓN/FEMINIZACIÓN POR ÁREA DE GESTIÓN Y POR DEPENDENCIA}

La literatura sostiene que las áreas de gestión gubernamentales tienden a presentar perfiles de género relativamente diferenciados y estables en el tiempo. Las mujeres habrían tenido más espacio en las áreas sociales, vinculadas con las tareas de cuidado, como Desarrollo Social, Salud, Educación o Cultura, mientras que las áreas económicas (Economía, Hacienda, Finanzas, Agricultura, etc.) y políticas (Interior, JGM, SP, Relaciones Exteriores, etc.) habrían estado reservadas para los varones, configurando «techos de cristal» al avance de las mujeres (Caminotti et al., 2011; Grassi, 1989).

Clasificar en grandes «áreas» la diversidad de dependencias que integraron los gabinetes de 2011, 2015 y 2019 puede ser dificultosa, por ejemplo, por las unificaciones o los cambios de jerarquías o de nominación. Sin embargo, algunos estudios (Giorgi, 2014; Joignant, 2011) han ensayado distintos agrupamientos, tomando como referencia cierta estabilidad en las funciones cumplidas por las diferentes carteras.

Aquí se propone una clasificación en tres grandes «áreas de gestión», o «áreas gubernamentales» (Joignant, 2011), de acuerdo con la función primordial que cumplieron en el conjunto del organigrama y en el largo plazo. Dentro del «área social» se incluyen los ministerios de Desarrollo Social, Trabajo, Salud, Educación, Cultura, Desarrollo Territorial y Mujeres, Géneros y Diversidad; dentro del «área político-institucional», a la JGM, a las SP y a los ministerios de Relaciones Exteriores, Justicia y Derechos Humanos, Seguridad, Defensa, Modernización e Interior; finalmente, en el «área económico-productiva», a los ministerios de Economía, Hacienda, Finanzas, Industria, Agricultura, Planificación, Obras Públicas, Agroindustria, Producción, Transporte, Ciencia y Tecnología, Turismo, Ambiente, Desarrollo Productivo, Comunicaciones, Energía y Minería.

Se observa que cada una de estas tres grandes áreas presenta una composición de género diferenciada en los gobiernos analizados (Gráfico 5):

Entre 2011 y 2019 la presencia de las mujeres aumentó en las tres áreas de gestión. Sin embargo, en 2015 retrocedieron en dos de las tres áreas: la político-institucional, donde la participación femenina se redujo en casi 1 punto y medio, y la económico-productiva, donde el retroceso fue de 2 puntos en relación con la elite gubernamental anterior. 


\section{GRÁFICO 5. PRESENCIA DE ALTAS FUNCIONARIAS MUJERES (\%) POR ÁREAS DE GESTIÓN EN 2011, 2015 Y 2019}

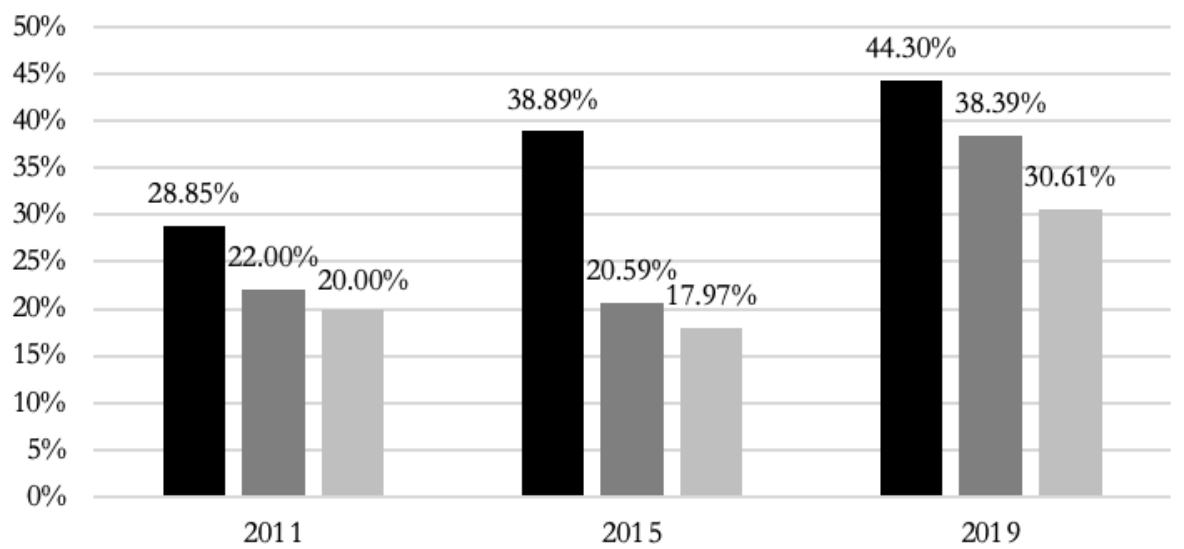

—Área social घárea político-institucional $\square$ Área económico-productiva

Fuente: Observatorio de las Elites CITRA (CONICET-UMET).

En los tres elencos las mujeres predominaron claramente en el área social por encima de las otras dos áreas, y en 8 años su presencia creció allí más de 15 puntos: del 28,85\% en 2011, al 38,89 \% en 2015, al 44,30 \% en 2019. El área más restringida a las mujeres fue la económico-productiva, que entre 2011 y 2019 fue uno de los «techos de cristal» de estos espacios ejecutivos, a pesar de que en 2019 la presencia femenina creció al 30,61 \%.

$\mathrm{El}$ área político-institucional se mantuvo siempre en valores intermedios a los de las dos anteriores: las mujeres ocuparon alrededor del $20 \%$ de los cargos vinculados con esta área, tanto en 2011 como en 2015. En 2019 su presencia aumentó al 38,39 \%, una particularidad del reclutamiento de Fernández que abrió relativamente esta área gubernamental a las mujeres.

Este avance generalizado de las mujeres, tanto en el total de cada gobierno como en las diferentes áreas de gestión, encubre algunas tendencias que muestran algunas dependencias puntuales, donde a lo largo del tiempo se profundizaron o bien la masculinización o bien la feminización.

Entre las dependencias que se masculinizaron a lo largo del tiempo encontramos a los ministerios de Relaciones Exteriores, de Planificación/Obras Públicas, de Trabajo, Empleo y Seguridad Social y de Transporte (Gráfico 6): 


\section{GRÁFICO 6. PARTICIPACIÓN DE ALTAS FUNCIONARIAS MUJERES (\%) EN RELACIONES EXTERIORES, OBRAS PÚBLICAS, TRABAJO Y TRANSPORTE, 2011, 2015 Y 2019}

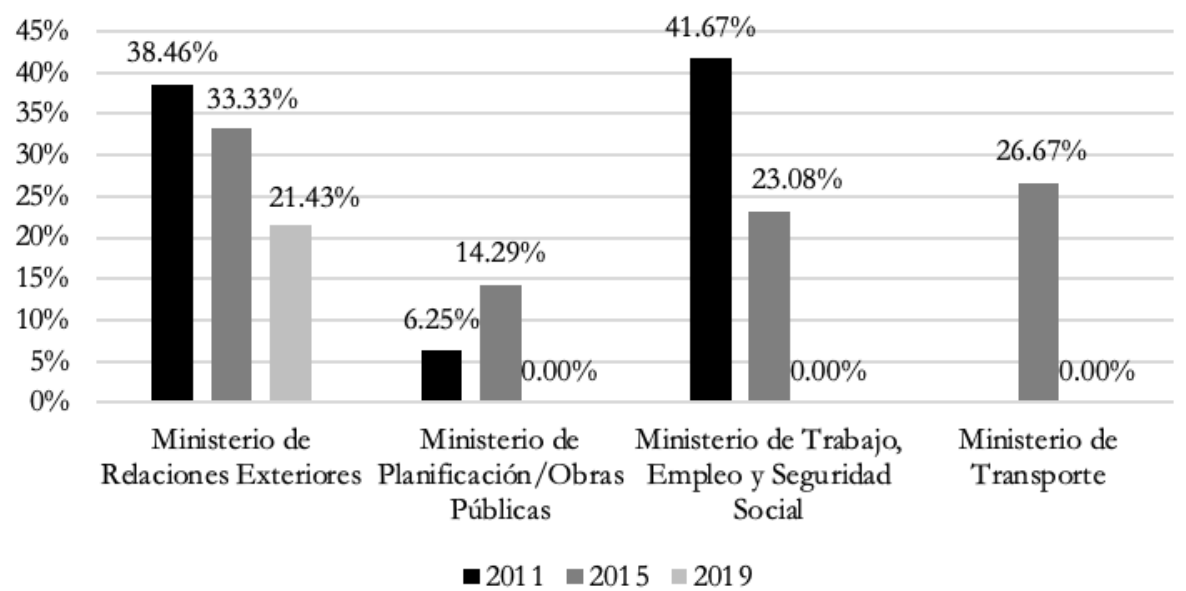

Fuente: Observatorio de las Elites CITRA (CONICET-UMET).

En el Ministerio de Relaciones Exteriores la participación de las mujeres perdió 17 puntos en 8 años: 38,46 \% en 2011, 33,33 \% en 2015 y 21,43 \% en 2019. Igual tendencia se observa en la cartera de Planificación/Obras Públicas: 6,25 \% de mujeres en 2011, 14,29 \% en 2015 y 0 \% en 2019. En el Ministerio de Trabajo, Empleo y Seguridad Social la presencia de altas funcionarias mujeres se redujo 41 puntos en 8 años: 41,67 \% en 2011, 23,08 \% en 2015 y 0 \% en 2019. Transporte, que recién alcanzó el estatus de ministerio en 2015, redujo la presencia de mujeres del 26,67 \% con Macri al $0 \%$ con Fernández.

En un segundo grupo se encuentran carteras que en general corresponden al área político-institucional, muy masculinizadas, pero que en 2019 experimentaron un considerable avance femenino: el Ministerio del Interior, la JGM, las SP y el Ministerio de Defensa (Gráfico 7):

En 2011 el Ministerio del Interior no tenía ninguna mujer integrando su cúpula, pero en 2015 las mujeres representaban un 14,29 \% y en 2019 un 33,33\%. En la JGM la presencia de las mujeres aumentó del $12 \%$ en 2011, al 30,43 \% en 2015 y al 36,67 \% en 2019. Se observa la misma tendencia en las SP, que pasaron de tener un 16,67\% de mujeres en 2011, a un $18,18 \%$ en 2015 y a un 37,50 \% en 2019. Dentro de este grupo el Ministerio de Defensa es un caso para destacar: generalmente incluido dentro de las áreas gubernamentales más masculinizadas, el avance de las mujeres en su alto funcionariado fue muy importante: del $10 \%$ en 2011, al $0 \%$ durante el gobierno de Macri y al 38,46 \% en 2019. 


\section{GRÁFICO 7. PARTICIPACIÓN DE ALTAS FUNCIONARIAS MUJERES EN INTERIOR, JGM, SECRETARÍAS DE LA PRESIDENCIA Y DEFENSA, 2011, 2015 Y 2019}

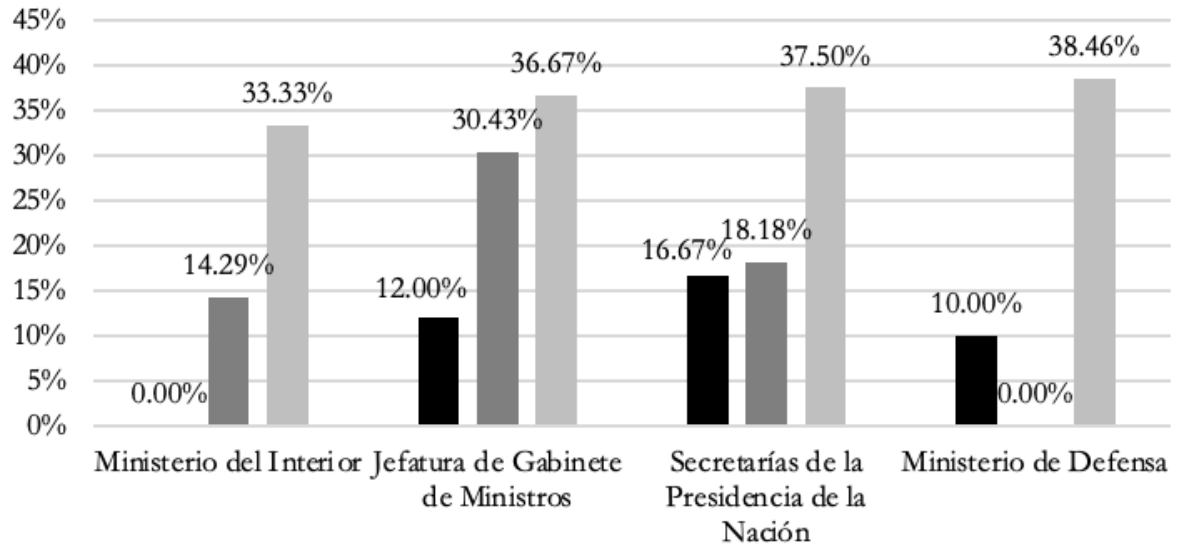

- $2011 \square 2015 \square 2019$

Fuente: Observatorio de las Elites CITRA (CONICET-UMET).

Finalmente, se observa un tercer grupo de dependencias que muestran una presencia femenina estable a lo largo del tiempo y, en algunos casos, una profundización de la feminización: es el caso de Desarrollo Social, de Educación, de Seguridad, y de Mujeres, Géneros y Diversidad (Gráfico 8):

Desarrollo Social creció en presencia de mujeres desde un 31,58 \% en 2011 a un $60 \%$ en 2015 (fue el área más feminizada del gobierno de Macri), y en 2019 redujo esa feminización a un 41,18 \%. Educación presenta una feminización creciente: $25 \%$ en 2011, 30,77 \% en 2015 y $53,33 \%$ en 2019 , año en que se transformó en el tercer ministerio con más presencia de mujeres. Seguridad sufrió fluctuaciones: de ser la dependencia más feminizada del gabinete de Fernández de Kirchner, la única con paridad de género, se masculinizó durante el gobierno de Macri con solo un 15,38 \% de mujeres (a pesar de que entonces fue conducida por una mujer, Patricia Bullrich); y en 2019 se transformó en la segunda dependencia del gabinete en presencia femenina $(61,54 \%)$. Finalmente en este tercer grupo de carteras feminizadas se destaca el Ministerio de las Mujeres, Géneros y Diversidad, creado en 2019, con una cúpula integrada netamente por mujeres, como mencionamos. 


\section{GRÁFICO 8. PARTICIPACIÓN DE ALTAS FUNCIONARIAS MUJERES (\%) EN DESARROLLO SOCIAL, EDUCACIÓN, SEGURIDAD Y MUJERES, GÉNEROS Y DIVERSIDAD, 2011, 2015 Y 2019}

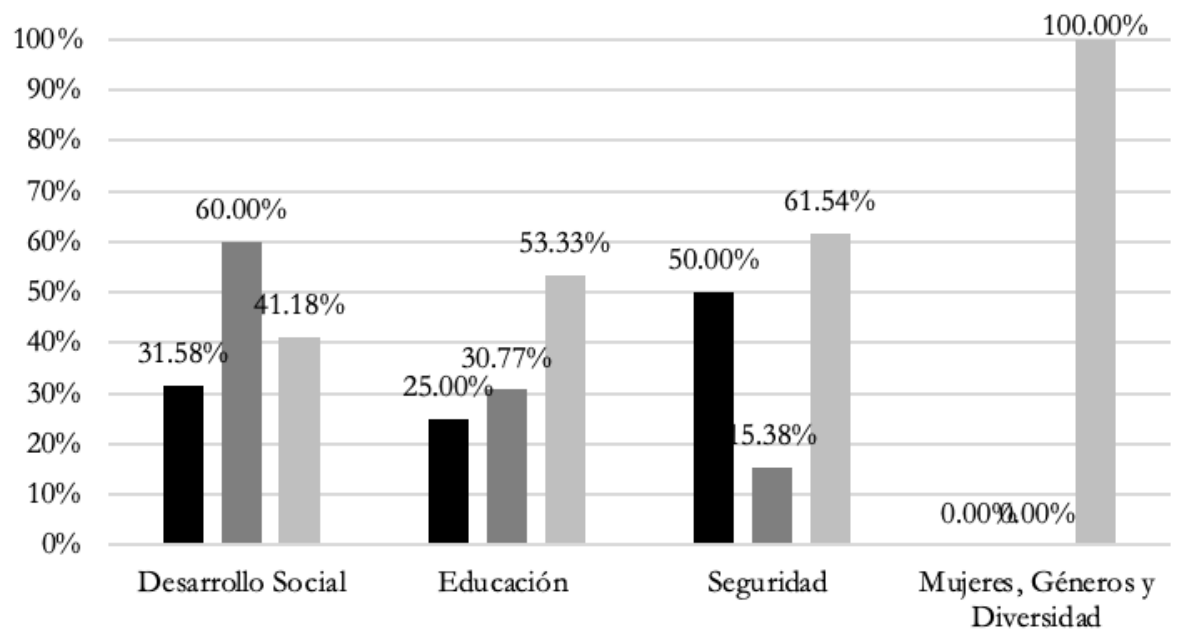

ロ $2011=2015 \square 2019$

Fuente: Observatorio de las Elites CITRA (CONICET-UMET).

\section{CARGOS JERÁRQUICOS Y GÉNERO}

Una cuestión central del vínculo entre género y poder político es la de las jerarquías, porque aun dentro de los espacios más altos del poder se definen subjerarquías internas que pueden constituir verdaderos «techos de cristal». En este sentido, como se afirmó más arriba, la literatura comparada muestra que las mujeres tendieron a ocupar los cargos jerárquicos más bajos y a estar generalmente ausentes del de ministra (Escobar-Lemmon y Taylor-Robinson, 2008; Krook y O’Brien, 2012).

Los gráficos que se presentan a continuación muestran para qué tipo de cargo de los analizados en este artículo (ministro, secretario, subsecretario) fueron reclutadas las mujeres en los gobiernos de Fernández de Kirchner, Macri y Fernández (Gráfico 9).

En 2011 las mujeres fueron minoría en los tres tipos de cargo, con un peso similar en todos ellos y con una leve tendencia a ocupar los cargos más bajos. Sobre un total de 16 cargos de ministro, las mujeres ocuparon solo 3 (19 \%): Alicia Kirchner, ministra de Desarrollo Social; Debora Giorgi, ministra de Industria; y Nilda Garré, ministra de Seguridad. Este reducido peso de las mujeres se mantuvo en las segundas líneas jerárquicas: las secretarias fueron solo un $20 \%$ y las subsecretarias un $25 \%$. 

MACRI Y FERNÁNDEZ

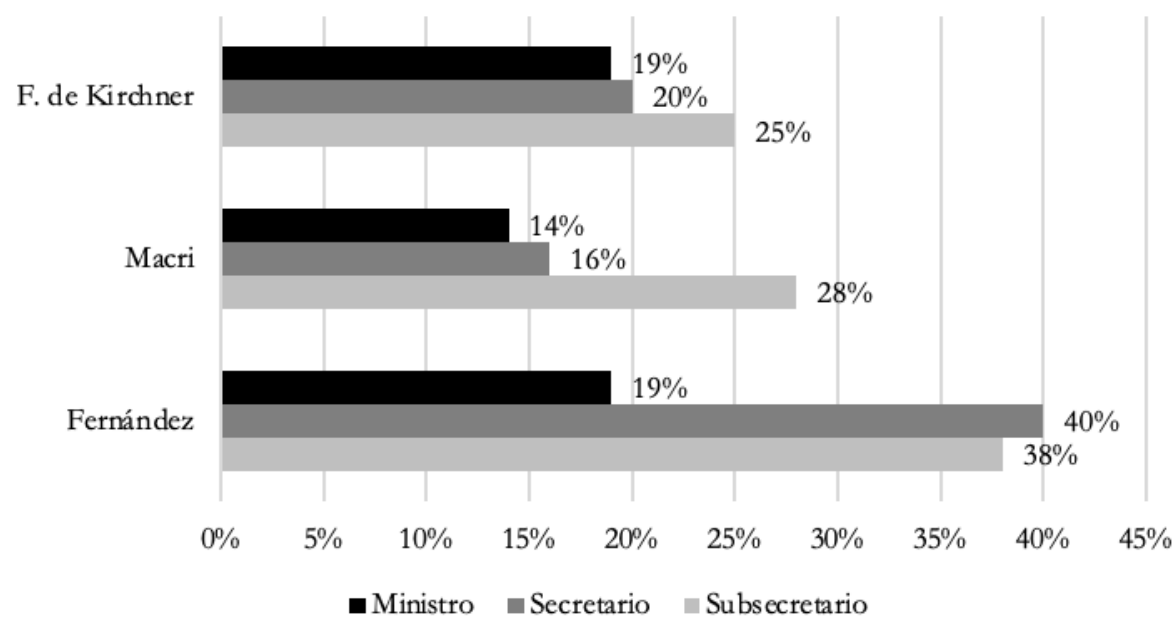

Fuente: Observatorio de las Elites CITRA (CONICET-UMET).

En 2015 las mujeres también fueron minoría, pero además su jerarquía se redujo. Sobre un total de 21 cargos de ministro, fueron solo 3 (14 \%): Carolina Stanley, ministra de Desarrollo Social; Susana Malcorra, ministra de Relaciones Exteriores; y Patricia Bullrich, ministra de Seguridad. En las segundas líneas, las mujeres secretarias se redujeron al $16 \%$ y las subsecretarias el $28 \%$ del total de este tipo de cargo.

Las designaciones de 2019 permitieron el ascenso de las mujeres en las jerarquías de la elite gubernamental. Aunque continuaron siendo minoría, aumentó su presencia en las dos jerarquías inferiores, concretamente en el nivel de las secretarías, donde avanzaron del $16 \%$ en 2015 al $40 \%$; las subsecretarias mujeres, por su parte, crecieron del $28 \%$ de 2015 al $38 \%$.

Sin embargo, también aquí se advierte un «techo de cristal» que bloquea el avance de las mujeres, incluso en una elite más paritaria como la de 2019. Se trata de su relativa exclusión de la posición más alta del gabinete, el cargo de ministro, donde avanzaron menos que en las segundas líneas, sin lograr superar nunca el $19 \%$. Con 21 cargos de ministro disponibles, Fernández solo designó a 4 mujeres: María Eugenia Bielsa, ministra de Desarrollo Territorial y Hábitat'; Marcela Losardo, ministra de Justicia y Derechos Humanos; Sabina Frederic, ministra de Seguridad; y Elizabeth Gómez Alcorta, ministra de las Mujeres, Géneros y Diversidad.

3. En 2020 renunció la ministra de Desarrollo Territorial y Hábitat y fue reemplazada por un hombre: esto redujo a las ministras mujeres de la presidencia de Fernández al 14,28 \% del total de ministros. 
Ahora bien, una consecuencia importante de la relativa ausencia de ministras puede ser el impacto en la composición de género de las jerarquías inferiores. ¿Reclutan mujeres las mujeres cuando llegan a altas posiciones de poder? El Gráfico 10 muestra que en 2011, 2015 y 2019 los ministerios conducidos por mujeres presentaron mayor igualdad de género en sus segundas líneas que aquellos conducidos por hombres:

\section{GRÁFICO 10. RECLUTAMIENTO DE FUNCIONARIAS MUJERES (\%) SEGÚN SEXO DEL/LA MINISTRO/A, 2011, 2015 Y 2019}

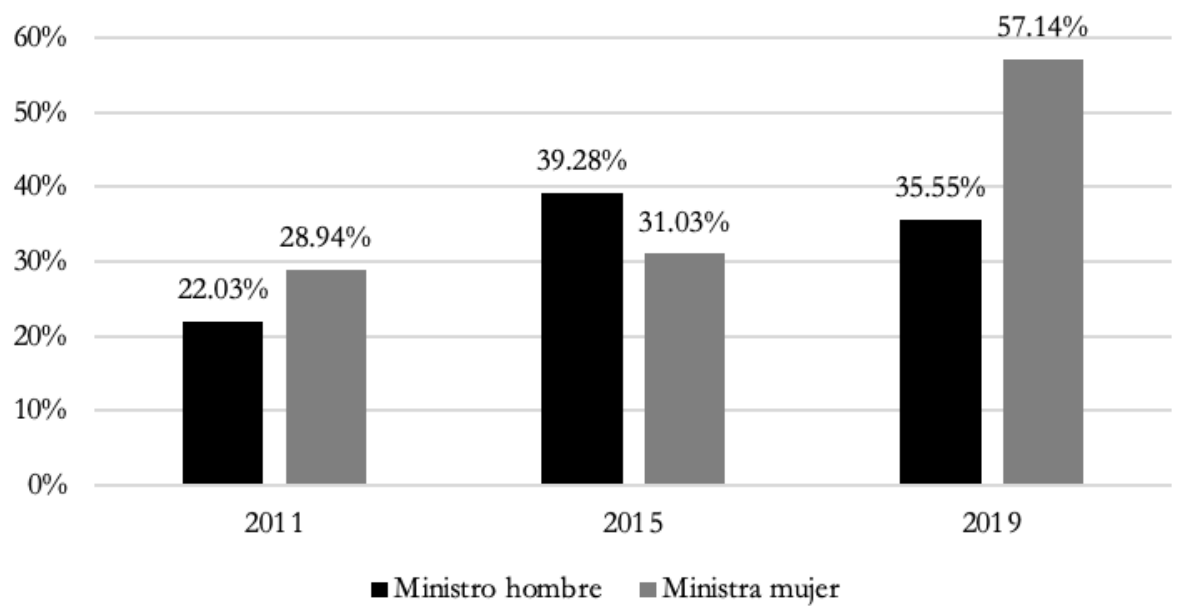

Fuente: Observatorio de las Elites CITRA (CONICET-UMET).

Como en otros aspectos analizados en este artículo, la elite gubernamental de Macri marcó una excepción a la tendencia: en 2015, considerados en conjunto, los ministerios liderados por mujeres reclutaron un porcentaje menor de mujeres que los liderados por hombres. Es probable que aquí haya tenido incidencia la concepción conservadora sobre el rol de la mujer de esta fuerza política (Canelo, 2019).

Por el contrario, los altos elencos ejecutivos de 2011 y 2019 confirman la asociación entre ministra mujer/composición de género más igualitaria de la elite gubernamental. En ambos casos, el conjunto de dependencias lideradas por mujeres reclutó mayor proporción de personal político femenino que el conjunto de las conducidas por hombres. En el gobierno de Fernández de Kirchner las carteras conducidas por mujeres reclutaron un 28,94 \% de mujeres, 7 puntos más que las que tenían ministros varones. Con Fernández esta tendencia se consolidó: las mujeres ministras reclutaron un $57,14 \%$ de personal femenino, frente al $35,55 \%$ que reclutaron los ministros hombres; más de 21 puntos de diferencia.

Para concluir, entre 2011 y 2019 los ministerios conducidos por mujeres aumentaron la tendencia a reclutar mujeres en 28 puntos: del 28,94 \% al 57,14 \%. Esto sugiere que, con excepción del gabinete 2015, con el paso del tiempo y en el caso argentino, la decisión de 
reclutar a una ministra mujer se ha vuelto un elemento decisivo para avanzar hacia una mayor paridad de género en las jerarquías inferiores.

\section{CONCLUSIONES}

Este trabajo mostró que en los últimos años en Argentina las elites gubernamentales ejecutivas avanzaron hacia una mayor participación política femenina. Sin embargo, dado que el Poder Ejecutivo argentino es una «institución generizada» donde el género está presente en los procesos, prácticas, imágenes e ideologías y distribuciones del poder (Kenney, 1996) y teniendo en cuenta que dichas instituciones producen, reproducen y transforman patrones de desigualdad de género (Caminotti et al., 2011), no es sorpresivo que ese avance también incluya claroscuros.

Si se observa la participación de las mujeres sobre el total de estos altos elencos ejecutivos, se constata que Fernández de Kirchner y Macri mantuvieron un reclutamiento de género muy similar en sus respectivas elites gubernamentales, a pesar de sus notables diferencias de orientación ideológica y política. En ninguno de los dos casos las mujeres llegaron a un cuarto del total de los funcionarios más altos. En contraste, las elites ejecutivas que acompañaron a Fernández marcaron un importante salto hacia la igualdad de género: las funcionarias mujeres representaron el 37,37 \% del total. Además, la elite gubernamental de 2019 mostró una orientación más clara hacia la paridad de género general.

Sin embargo, una mirada atenta sobre la participación femenina en las distintas dependencias y áreas de gestión muestra un panorama más heterogéneo y complejo.

Primero, en cuanto a las dependencias, se observa un primer conjunto que, independientemente de la tendencia general al avance de las mujeres, profundizó su masculinización, con indicadores poco variables entre los distintos gobiernos. Se trata de los ministerios de Relaciones Exteriores, de Planificación/Obras Públicas, de Trabajo, Empleo y Seguridad Social y de Transporte, las dependencias más establemente masculinizadas de los últimos años. En segundo lugar se advierte otro grupo de dependencias muy masculinizadas, que en general cumplen funciones de tipo político, pero que a partir de la administración de Fernández habilitaron un progresivo avance femenino: Interior, la JGM, las SP y el Ministerio de Defensa. En tercer lugar se consagra un conjunto bastante estable de dependencias muy feminizadas: los ministerios de Desarrollo Social, Educación, Seguridad y Mujeres, Géneros y Diversidad.

Segundo, al observar las diferentes áreas de gestión se advierte que presentaron una composición de género disímil. Confirmando las tendencias ya señaladas por la literatura (Caminotti et al., 2011; Grassi, 1989; Salerno, 2019), en las tres elites gubernamentales las mujeres predominaron en el área social por encima de las otras dos áreas, mientras que la económico-productiva fue la más reacia a la incorporación de mujeres, por lo que puede afirmarse que sigue constituyendo un «techo de cristal» para la paridad. Sin embargo, el reclutamiento más igualitario realizado en el área político-institucional a partir de 2019 parece desafiar las tendencias identificadas por la literatura especializada, y las mujeres parecen estar comenzando a ocupar posiciones en las áreas de este tipo, de las que tradicionalmente estuvieron apartadas; no hay que perder de vista que, de todas formas, en el gabinete de Fernández los más altos funcionarios de las áreas político-institucionales son casi todos hombres. 
En cuanto al vínculo entre jerarquías y género cabe preguntarse si las funcionarias mujeres lograron, además de aumentar su presencia en el conjunto de las elites gubernamentales ejecutivas y en algunas áreas de gestión y dependencias específicas, ocupar cargos jerárquicos más altos que en el pasado. Si no, ¿cuáles son los «techos de cristal» que obstaculizan su ascenso en estos espacios ejecutivos?

Confirmando lo que señala la bibliografía (Krook y O’Brien, 2012) en los tres elencos, 2011, 2015 y 2019, las mujeres fueron minoría frente a los hombres en todos los cargos analizados y, además, fueron reclutadas en general para ocupar los más bajos. Las designaciones de Fernández en 2019 habilitaron su relativo ascenso en la jerarquía, pero solo hasta las segundas líneas, secretarías y subsecretarías, mientras que continuaron relativamente excluidas del cargo de ministra.

El análisis realizado permitió identificar al menos tres tipos de «techo de cristal» que siguen determinando la desigualdad de género en el Ejecutivo Nacional argentino. El primero es la relativa exclusión de las mujeres del cargo de ministro: estas nunca superaron el $19 \%$ del total de las posiciones, una tendencia que permanece inamovible. El segundo está vinculado con la existencia de muchas dependencias conducidas por ministros hombres que, a contracorriente de la tendencia general, continúan sin reclutar mujeres o bien reclutan un porcentaje mínimo de personal femenino. Los casos más notorios fueron Interior en 2011, Ciencia y Tecnología y Defensa en 2015 y Transporte, Trabajo y Obras Públicas en 2019, además de carteras como Relaciones Exteriores donde la participación femenina en las elites gubernamentales viene retrocediendo hace tiempo. El tercer «techo de cristal» es la reticencia, salvo excepciones, de quienes conducen las áreas que llamamos económicoproductivas (Economía, Hacienda, Finanzas, Industria/Agroindustria, Energía y Minería, etc.) a reclutar personal político femenino, reticencia más pronunciada aún que la de las áreas político-institucionales.

La evidencia empírica revelada y analizada no permite extraer conclusiones sobre las diferencias entre la «representación descriptiva» (es decir, la presencia de miembros de un grupo social determinado en un órgano gubernamental, que mejora cuando la proporción se acerca a la real de ese grupo en la población) y la «representación sustantiva» (o la promoción de los intereses de un grupo en el proceso de toma de decisiones) (Martínez y Garrido, 2013; Ríos Tobar y Villar, 2005); o, en otros términos, entre la «presencia» y la «acción» o la «agencia». Pero sí muestra que, al menos en lo referido a los últimos tres gobiernos argentinos, la llegada al poder de una presidenta mujer no determinó una composición de género más igualitaria de las elites gubernamentales. Pero que, sin embargo, el sexo de los ministros sí incidió en el de sus colaboradores: puntualmente, los ministerios conducidos por mujeres presentaron mejores indicadores de género que los de sus pares hombres.

Los elencos 2011 y 2019 (aunque no así el de 2015) confirman una importante asociación entre ministra mujer/composición de género más igualitaria de su dependencia. En los gobiernos de Fernández de Kirchner y de Fernández las carteras lideradas por mujeres reclutaron, en conjunto, mayor proporción de personal político femenino que las conducidas por hombres. Esta asociación se volvió, además, cada vez más determinante con el paso del tiempo: mientras que en el gabinete de Fernández de Kirchner las dependencias conducidas por ministras reclutaron 7 puntos más de mujeres que las conducidas por ministros, en el 
gabinete de Fernández la brecha se amplió a más de 21 puntos. Esto significa que, con excepción del gabinete 2015, la decisión de reclutar a una ministra mujer es cada vez más decisiva y eficaz para lograr una mayor igualdad de género, al menos en lo que a representación descriptiva (Martínez y Garrido, 2013) respecta.

Finalmente, ¿qué factores podrían explicar las modificaciones en las dinámicas de reclutamiento de las elites gubernamentales que mostramos en este trabajo?

Primero, en términos generales, la tendencia hacia una mayor paridad en los espacios de toma de decisiones es sin duda inseparable de las luchas y conquistas del movimiento de mujeres, que en gran parte de los países de América Latina logró una mayor permeabilidad y atención de los gobernantes a sus demandas (Rodríguez, 2003) e incluso, probablemente, a instalar cierta preferencia por los liderazgos femeninos sobre los masculinos (Fernández Poncela, 2012). Como señalamos más arriba, incluso el gobierno de centro-derecha de Macri, portador de una concepción tradicional del rol de la mujer, viabilizó un ascenso inédito de mujeres a los más altos cargos políticos: vicepresidenta, gobernadora de la provincia más importante del país, ministras, legisladoras que jugaron un rol importante en la aprobación de distintas iniciativas y políticas de género, etc. La agenda de género, en efecto, ya es parte del campo de batalla cultural en el que disputan las derechas en la región, plano en el que ya han dado importantes pasos (Giordano y Rodríguez, 2020).

Segundo, la mayor tendencia a la paridad de género que muestran los elencos de Fernández en relación con las otras dos elites políticas analizadas puede explicarse por la composición política de la coalición que lo llevó al gobierno, el Frente de Todos. Este frente incluyó no solo a tres corrientes peronistas diferentes (los llamados «albertismo», «kirchnerismo»y «massismo», por el apellido de sus respectivos líderes), sino además a tres vertientes sociopolíticas diferenciadas: la de la política profesional, la de la academia y los científicos, y la de los movimientos socioterritoriales y feministas (Longa y Vázquez, 2020). Es así que la mayor presencia de las mujeres en las elites gubernamentales de 2019 puede explicarse, en gran parte, por la naturaleza de la coalición política en el poder.

Ambas hipótesis, que sería importante profundizar en futuras investigaciones, no descartan de todas formas la posibilidad de que los avances hacia la igualdad de género aquí descritos puedan ser más coyunturales que estructurales. Especialmente porque, como también se mostró, aún persisten importantes barreras de larga data contrarias a la paridad en los ejecutivos.

La experiencia en otros altos espacios de gobierno, como el legislativo, muestra que la ampliación de la participación femenina no fue, en general, un proceso ni gradual ni armónico, sino el resultado de la incorporación deliberada, conflictiva y muchas veces resistida (Archenti y Tula, 2019; Caminotti et al., 2011) de medidas concretas, como las cuotas de género. Esta experiencia sugiere que es fundamental continuar aportando no solo evidencia empírica que contribuya a la reducción de las desigualdades políticas, sino también continuar abriendo espacios de debate en la agenda pública y política sobre la necesariedad, legitimidad y oportunidad de avanzar institucionalmente: puntualmente, con la sanción de leyes de paridad de género en los ejecutivos, que consagren, como sucedió en los espacios legislativos, oportunidades equitativas de acceso a la representación (Archenti y Tula, 2019). 


\section{BIBLIOGRAFÍA}

Abu-Zayd, G., Méndez-Montalvo, M., Ballington, J. e International Institute for Democracy and Electoral Assistance (Eds.). (2002). Mujeres en el Parlamento: Más allá de los números (ed. en español). International IDEA.

Alcántara Sáez, M. (2006). Politicos y politica en América Latina. Siglo XXI de España Editores.

Araújo, C. (2009). Gênero e acesso ao poder legislativo no Brasil: As cotas entre as instituições e a cultura. Revista Brasileira de Ciencia Politica, 2, 23-59.

Archenti, N. y Tula, M. I. (2014). Cambios normativos y equidad de género. De las cuotas a la paridad en América Latina: los casos de Bolivia y Ecuador. América Latina Hoy, 66, 47. https://doi.org/10.14201/ alh2014664768

Archenti, N. y Tula, M. I. (2019). Teoría y política en clave de género. Colección, 30(1), 13-43.

Baldez, L. (2002). Why Women Protest: Women's Movements in Chile. Cambridge University Press. https://doi. org/10.1017/CBO9780511756283

Barnes, T. D., Ciocci, T. y Lopreite, D. (2019). Evaluación de la presencia de mujeres en gabinetes subnacionales de Argentina (1992-2016). Revista de Ciencia Politica), 39(1), 1-23. https://doi.org/10.4067/ s0718-090x2019000100023

Basabe-Serrano, S. (2020). La subrepresentación de mujeres en gabinetes ministeriales: El caso ecuatoriano en perspectiva comparada, 1979-2015. Latin American Research Review, 55, 31-48. https://doi. org/10.25222/larr.204

Bego, I. (2014). Accessing Power in New Democracies: The Appointment of Female Ministers in Postcommunist Europe. Political Research Quarterly, 67(2), 347-360. https://doi.org/10.1177/1065912913509028

Camerlo, M. (2013). Gabinetes de partido único y democracias presidenciales. Indagaciones a partir del caso argentino. América Latina Hoy, 64, 119-142. https://doi.org/10.14201/alh.10245

Caminotti, M. y Cogliano, N. D. (2019). El origen de la «primera generación» de reformas de paridad de género en América Latina: Evidencia de Argentina. Politica y Gobierno, 26(2), 205-218. http://www. politicaygobierno.cide.edu/index.php/pyg/article/view/1298

Caminotti, M. y Freidenberg, F. D. (2016). Federalismo electoral, fortaleza de las cuotas de género y representación política de las mujeres en los ámbitos subnacionales en Argentina y México. Revista Mexicana de Ciencias Politicas y Sociales, 61(228), 121-144. http://dx.doi.org/10.1016/S0185-1918(16)30042-3

Caminotti, M., Rotman, S. y Varetto, C. (2011). Carreras políticas y oportunidades «generizadas» en la Provincia de Buenos Aires, Argentina (1983-2007). PostData, 16(2), 191-222.

Canelo, P. (2019). ¿Cambiamos?: La batalla cultural por el sentido común de los argentinos. Siglo XXI Editores.

Canelo, P. y Castellani, A. (2016). Perfil sociológico de los miembros del gabinete inicial del presidente Mauricio Macri. Informe de Investigación n. ${ }^{\circ}$ 1; Informes del Observatorio de las Elites (pp. 1-37). CITRA (CONICET-UMET). https://citra.org.ar/wp-content/uploads/2020/01/2016_Informe_1_Observatorio_de_las_Elites.pdf

Canelo, P., Castellani, A. y Heredia, M. (2015). Perfil sociológico de las elites políticas, económicas y tecnocráticas entre 1976 y 2001 [ponencia]. XI Jornadas de Sociología, Buenos Aires, Argentina. https://www.aacademica. org/000-061/721

Canelo, P. y Lascurain, M. C. (2017). ¿Quiénes gobiernan la Provincia de Buenos Aires? El perfil sociológico del gabinete de María Eugenia Vidal. Informe de Investigación n. ${ }^{\circ}$ 3; Informes del Observatorio de las Elites (pp. 1-28). CITRA (CONICET-UMET). https://citra.org.ar/wp-content/uploads/2020/01/2017_Informe_3_Observatorio_de_las_Elites.pdf 
Chasquetti, D., Buquet, D. y Cardarello, A. (2013). La designación de gabinetes en Uruguay: Estrategia legislativa, jerarquía de los ministerios y afiliación partidaria de los ministros. América Latina Hoy, 64, 15-40. https://doi.org/10.14201/alh.10230

Claveria, S. (2014). Still a 'Male Business'? Explaining Women's Presence in Executive Office. West European Politics, 37(5), 1156-1176. https://doi.org/10.1080/01402382.2014.911479

Codato, A., Perissinotto, R., Bolognesi, B., Costa, L., Massimo, L. y Neves Costa, P. (2018). La sociología política de las elites políticas y estatales de Brasil: Un balance de cincuenta años de estudios. En G. Vommaro y M. Gené (Comps.), Las élites politicas en el Sur: Un estado de la cuestión de los estudios sobre la Argentina, Brasily Chile (pp. 21-89). UNGS.

Craske, N. y Molyneux, M. (2002). Gender and the Politics of Rights and Democracy in Latin America. AIAA.

D’Alessandro, M. (2016). Economía feminista: Cómo construir una sociedad igualitaria (sin perder el glamour). Penguin Random House Grupo Editorial Argentina.

Dávila, M., Lavados, A. O. y Avendaño, O. (2013). Los gabinetes de la Concertación en Chile (1990-2010). América Latina Hoy, 64, 67-94. https://doi.org/10.14201/alh.10232

De Luca, M. A. de. (2012). Del príncipe y sus secretarios: Cinco apuntes sobre gabinetes presidenciales en la Argentina reciente. En A. Malamud, y M. A. de Luca (Coords.), La política en tiempos de los Kirchner (pp.37-48). Eudeba (pp. 37-48).

De Winter, L. (1991). Parliamentary and Party Pathways to the Cabinet. En J. Blondel y J.-L. Thiébault (eds.), The Profession of Government Minister in Western Europe (pp. 44-69). Palgrave Macmillan UK. https:// doi.org/10.1007/978-1-349-11395-8_5

Escobar-Lemmon, M. y Taylor-Robinson, M. M. (2005). Women Ministers in Latin American Government: When, Where and Why? American Journal of Political Science, 49(4), 829-844. https://doi. org/10.1111/j.1540-5907.2005.00158.x

Escobar-Lemmon, M. y Taylor-Robinson, M. M. (2008). Getting to the Top: Career Paths of Women in Latin American Cabinets. Political Research Quarterly, 62(4), 685-699. https://doi. org/10.1177/1065912908322414

Fernández Poncela, A. M. (2012). Desconfianza en la clase política y preferencias hacia las mujeres políticas. Polis, 8(2), 175-209.

Fleischer, J. y Seyfried, M. (2015). Drawing from the bargaining pool: Determinants of ministerial selection in Germany. Party Politics, 21(4), 503-514. https://doi.org/10.1177/1354068813487108

Gené, M. y Vommaro, G. (Coords.) (2018). Las élites politicas en el Sur. Un estado de la cuestión de los estudios sobre la Argentina, Brasil y Chile. Ediciones UNGS. https://ediciones.ungs.edu.ar/libro/ las-elites-politicas-en-el-sur/

Giordano, V. y Rodríguez, G. P. (2020). Las mujeres de las derechas latinoamericanas del siglo XXI. Revista CIDOB d'Afers Internacionals, 126, 215-238. https://doi.org/10.24241/rcai.2020.126.3.215

Grassi, E. (1989). La mujer y la profesión de asistente social. El control de la vida cotidiana. Humanitas.

Giorgi, G. (2014) Ministros y ministerios de la Nación argentina: un aporte prosopográfico para el estudio del gabinete nacional (1854-2011). Apuntes, Revista de Ciencias Sociales, 41(74), 103-139.

Inglehart, R. y Norris, P. (2003). Rising Tide: Gender Equality and Cultural Change Around the World. Cambridge University Press.

Jalalzai, F. (2014). Gender, presidencies, and prime ministerships in Europe: Are women gaining ground? International Political Science Review, 35(5), 577-594. https://doi.org/10.1177/0192512114542112

Jalalzai, F. y Krook, M. L. (2010). Beyond Hillary and Benazir: Women's Political Leadership Worldwide. International Political Science Review, 31(1), 5-21. https://doi.org/10.1177/0192512109354470 
Joignant, A. (2011). Tecnócratas, technopols y dirigentes de partido. Tipos de agentes y especies de capital en las élites gubernamentales de la Concertación (1990-2010). En A. Joignant y P. Güell (Eds.), Notables, tecnócratas y mandarines. Elementos de la sociología de las elites en Chile (1990-2010) (pp. 49-76). Ediciones UDP.

Joignant, A. y Güell, P. (Eds.) (2011). Notables, tecnócratas y mandarines. Elementos de sociología de las elites en Chile (1990-2010). Ediciones UDP. https://ediciones.udp.cl/libro/notables-tecnocratas-y-mandarines/

Kenig, O. y Barnea, S. (2009). The Selection of Ministers in Israel: Is the Prime Minister 'A Master of His Domain'? Israel Affairs, 15, 261-278. https://doi.org/10.1080/13537120902983015

Kenney, S. J. (1996). New Research on Gendered Political Institutions. Political Research Quarterly, 49(2), 445466. https://doi.org/10.1177/106591299604900211

Krook, M. L. y O'Brien, D. Z. (2012). All the President's Men? The Appointment of Female Cabinet Ministers Worldwide. The Journal of Politics, 74(3), 840-855. JSTOR. https://doi.org/10.1017/ s0022381612000382

Longa, F. y Vázquez, M. (2020). ¿'Tres ramas? La composición política del albertismo. Nación Trabajadora. https://lanaciontrabajadora.com/ensayo/gobierno-alberto/

Luengo, O. y Del Campo, E. (2008). El impacto de los sistemas electorales y las leyes de cuotas en los países andinos: Las elecciones legislativas en Bolivia, Ecuador y Perú. En N. Archenti y M. I. Tula (Eds.) Mujeres y politica en América Latina: Sistemas electorales y cuotas. Heliasta.

Martín, M. E. (2018). Parlamento y Género: El caso de Misiones, Argentina. 1983-2001. Editorial Académica Española.

Martínez, M. A. y Garrido, A. (2013). Representación descriptiva y sustantiva: La doble brecha de género en América Latina. Revista Mexicana de Sociología, 75(3), 407-438.

Paxton, P. y Kunovich, S. (2003). Women's Political Representation: The Importance of Ideology. Social Forces, 82, 87-113. https://doi.org/10.1353/sof.2003.0105

Perelmiter, L., Heredia, M. y Gené, M. (2012). «Hacia una socio-historia del gabinete nacional». PolHis, 9 , 284-290.

Perissinotto, R. M. y Codato, A. (2008). Apresentação. Por um retorno à Sociologia das Elites. Revista de Sociologia e Politica, 16(30), 7-15.

Pomares, J., Leiras, M., Page, M., Zárate, S. y Abdala, M. B. (2014). Los caballeros de la mesa chica. La lógica de designación de los gabinetes desde 1983. Análisis, 139, 12.

Reynolds, A. (1999). Women in the Legislatures and Executives of the World: Knocking at the Highest Glass Ceiling. World Politics, 51(4), 547-572.

Ríos Tobar, M. y Villar, A. (2005). Cuotas de Género: Democraciay Representación. FLACSO.

Rodríguez, V. E. (2003). Women in Contemporary Mexican Politics. University of Texas Press. https://www.jstor. org/stable/10.7560/771253

Salerno, A. (2019). Una nueva derecha embarrada: Perfiles de gestión PRO en torno a la cuestión social de la ciudad de Buenos Aires (2007-2015). Sociobistórica, 44, e083. https://doi.org/10.24215/18521606e083

Sotiropoulos, D. A. y Bourikos, D. (2002). Ministerial Elites in Greece, 1843-2001: A Synthesis of Old Sources and New Data. South European Society and Politics, 7(2), 153-204. https://doi. org/10.1080/13608740708539628

Valdés, T. (2010). El Chile de Michelle Bachelet. ¿Género en el poder? Latin American Research Review, 45, 248273. https://doi.org/10.1353/lar.2010.0036 
PAULA VERA CANELO

GÉNERO Y PODER EN ARGENTINA. LAS ELITES EJECUTIVAS DE FERNÁNDEZ DE KIRCHNER, MACRI Y FERNÁNDEZ

Verge, T. y Claveria, S. (2018). Recursos políticos de género: El caso de la oficina del partido. Party Politics, 24(5), 536-548. https://doi.org/10.1177/1354068816663040

Whitford, A., Wilkins, V. y Ball, M. (2007). Descriptive Representation and Policymaking Authority: Evidence from Women in Cabinets and Bureaucracies. Governance, 20(4), 559-580. https://doi. org/10.1111/j.1468-0491.2007.00372.x 